\title{
LA REPRESENTACIÓN LITERARIA DEL INDÍGENA EN UN CUENTO DE ALFONSO REYES
}

Carmen V. Vidaurre

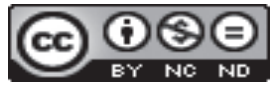

Doi: https://doi.org/10.15517/rfl.v46i2.42442

URL: https://revistas.ucr.ac.cr/index.php/filyling/index 



\title{
LA REPRESENTACIÓN LITERARIA DEL INDÍGENA EN UN CUENTO DE ALFONSO REYES
}

\author{
INDIAN LITERARY REPRESENTATION \\ IN A STORY BY ALFONSO REYES
}

Carmen V. Vidaurre

\begin{abstract}
RESUMEN
El estudio de "Silueta del indio Jesús", a partir de algunas propuestas metodológicas formuladas por Todorov, muestra la forma en que el indigenismo modernista que se manifiesta en el cuento rompe con algunas generalizaciones formuladas sobre ese movimiento literario, al mismo tiempo que revela las estrategias narrativas de un autor que confía en el sentido analítico de sus lectores para plantearles una reflexión sobre un problema social nacional, presentado desde un enfoque humanista y agudamente crítico, mediante la confrontación de dos perspectivas: la del narrador-personaje de la historia y la que deriva de las acciones y palabras del protagonista indígena del relato.

Palabras clave: Alfonso Reyes; indigenismo; modernismo; literatura mexicana; análisis literario.
\end{abstract}

\begin{abstract}
The study of "Silueta del indio Jesús", from some methodological proposals formulated by Torodov, shows the from in which the modernist indigenism, manifested in the story, breaks with some generalizations formed over this literary manifestation, at the same time that it reveals the strategic narratives of an author that trusts in the critical sense of his readers to make them reflect over a national social problem, presenting it over a humane focus and acutely critical, through the confrontation of two perspectives: the focus of the narrator-character of the story and the focus that derives of the words and actions of the indigenous protagonist of the story.

Keywords: Alfonso Reyes; indigenism; modernism; mexican literature; literary analysis.
\end{abstract}

\section{Introducción}

Si bien Alfonso Reyes formuló críticas contra el regionalismo practicado por autores como López Velarde (Reyes, 1941, 1953; Pacheco, 1975, pp. 153-159); igualmente se atrevió a tratar un tema ignorado por quienes incluso buscaron definirse como "nacionalistas": la problemática que enfrentaba un indígena en el contexto que le era contemporáneo, tema que no fue un asunto artístico y literario que surgiera de manera posterior a las políticas institucionales

Dra. Carmen V. Vidaurre Arenas. Universidad de Guadalajara. División de Artes y Humanidades del Centro Universitario de Arte, Arquitectura y Diseño. México.

Correo electrónico: maga2315@hotmail.com

Recepción: 13- 05- 19

Aceptación: 16-10-19 
del estado postrevolucionario en México: "El problema indígena, como bien lo han mostrado diversos estudios [...] resultó explícitamente expuesto en el discurso de las élites políticas e intelectuales a finales del siglo XIX, no obstante que bien podría situarse desde nuestros orígenes como nación independiente" (Mijangos Díaz y López Torres, 2011, p. 42). "Silueta del indio Jesús" nos muestra la forma en que Alfonso Reyes abordó el tema a principios del siglo XX. Se trata de un texto poco mencionado al estudiar la narrativa mexicana y el indigenismo literario, que como toda la narrativa breve de Reyes merece mayor atención, no únicamente porque Borges escribiera "Reyes ha sido uno de los mayores escritores de las diversas literaturas cuyo instrumento es la lengua española" (Borges y Reyes, 1998, p. 151), sino porque se trata de uno de los intelectuales más notables de México y cuyas obras han ejercido influencia en la producción literaria de muy célebres autores mexicanos posteriores, de manera destacada Carlos Fuentes, y de modos distintos Carlos Monsivaís, José Emilio Pacheco, Sergio Pitol, Hugo Iriart.

Aunque la enorme obra ensayística de Reyes, su poesía -en menor medida-, y uno de sus cuentos, "La cena", han sido estudiados ampliamente, son asombrosamente escasos los estudios sobre su producción narrativa, pese a que esta ha recibido elogios de renombrados escritores mexicanos, de los que únicamente mencionaremos a Julio Torri, por haber dejado testimonio temprano por escrito de su admiración en su epistolario. Entre los pocos investigadores que parcialmente la han estudiado se encuentran Luis Leal (1953), Ernesto Mejía Sánchez (1970), James Willis Robb (1989), Concha Meléndez (1995), Beatriz Espejo (2004), Adolfo Castañón (2007), Agapito Maestre (2010), Daniel Orizaga (2012) y Carlos Yanuzzi (2014).

"Silueta del indio Jesús" es considerado por algunos especialistas como el primer cuento de Reyes (Martínez, 1989), aunque en la reunión de cuentos prologada por Alicia Reyes (2010) se le ubica como el segundo cuento del autor. El texto forma parte de Vida y ficción, apartado con que inicia el volumen XXIII de las Obras Completas, del que José Luis Martínez señala que se trata de una "recopilación póstuma de narraciones" (1989, p. 9), escritas entre 1910 y 1959. Estudiamos este relato con base en algunas de las propuestas metodológicas de Tzvetan Todorov, considerando las instancias o niveles textuales que él destaca y define en su Poética (2004), obra en la que desarrolla una metodología de análisis estructuralista de los registros, el modo, el tiempo, las visiones, la voz (Todorov, 2004, pp. 62-91). Nuestro estudio busca también contextualizar el relato en relación con las tendencias literarias vigentes en la época de su producción e identificar los elementos que remiten a ellas, aunque este artículo está lejos de pretender desarrollar un estudio sobre estas, que ya han merecido destacados y abundantes trabajos. Respecto al modernismo, entre otras destacadas obras, se deben mencionar: Perus (1979), Gullón (1990), Litvak (1990), Gutiérrez Girardot (1987), Luna Sellés (2002), Acevedo (2002) y Schulman (2002), quienes ofrecen caracterizaciones diversas del movimiento. Respecto al indigenismo, enumeramos también algunas de las muchas investigaciones que registran distintas posturas: Mariátegui (1928), Meléndez (1939), Barreiro (1965), Gullón (1979), Cornejo (1977, 1978, 1979), León-Portilla (1975), Pacheco (1976), Rojas (1976), Portal (1975), Rama (1982). Movimientos literarios a los que solo nos referiremos de modo un tanto tangencial, porque su estudio no es el objetivo principal del presente escrito, ya que solo buscamos identificar los puntos de contacto que la obra analizada guarda respecto a ellos y compararlos con algunas generalizaciones sobre el modernismo y el indigenismo muy difundidas en México, que tienden a ignoran los casos que las contravienen. 
La narración que nos ocupa constituye, para James Willis Robb, una: "nueva refutación a aquellos críticos que insistían en que Reyes nunca manifestó preocupación por las tribulaciones del México moderno" (Robb, 1989, p. 836), porque desde los primeros párrafos es visible la denuncia de las condiciones de los indígenas en el país, primero mediante la explicación y comentario del narrador sobre el atuendo del protagonista: "Sólo el pantalón habido a última hora en sustitución del característico calzón blanco, para que lo dejaran circular por la ciudad los gendarmes" (Reyes, 1989a, p. 23), y después mediante el propósito manifiesto a lo largo del escrito de exponer la situación social que vivía un indígena antes de la Revolución Mexicana, hecho observado por algunos estudiosos de las obras de Reyes. Agapito Maestre, considera que basta con leer este cuento, para notar que se ha escrito una defensa de la libertad y una crítica certera al régimen vigente en la época (Maestre, 2010, pp. 30-31). Adolfo Castañón, en sus apuntes para una bibliografía crítica de Alfonso Reyes, señala la estrecha vinculación de Reyes con la realidad del país como un elemento clave para comprender, entre otras obras del escritor, este cuento (Castañón, 2005, p. 30). En Alfonso Reyes, caballero de la voz errante anota: "muchos de sus más acabados ejercicios críticos [son presentados] en forma de siluetas, retratos, anécdotas [...] 'La silueta del indio Jesús' ilustra esa facultad [...]" (Castañón, 2007, p. 157). Por su parte, Fernando Serrano Migallón, quien ha analizado los elementos jurídicos presentes en el texto, ha señalado que: "La Silueta del indio Jesús es un alegato por la integridad de la justicia [...], por el derecho a la educación y el desarrollo más allá de la mera retórica legalista" (Serrano, 2010, p. 18).

Es importante decir que nos encontramos ante un cuento en el que un narradorpersonaje citadino habla de un indígena y de sus problemas vitales, obra que por la fecha de su escritura (1910) correspondería a lo que para algunos de los especialistas en el tema se denomina "Indianismo modernista" (Escajadillo, 1972, p. 118), para otros corresponde al "Indigenismo modernista" (García, 1987, pp. 83 y 173; Peralta, 1995, p. 274), y para otros más al arranque del "Indigenismo contemporáneo" (Chang, 2009, p. 103 y ss.). Denominaciones distintas que buscan establecer una taxonomía cuyos criterios diferenciadores y cronológicos no son siempre claros, por lo que en el apartado correspondiente nos detendremos brevemente en algunos puntos al respecto.

\section{La voz, los registros, el modo, el tiempo en "Silueta del indio Jesús"}

En "Silueta del indio Jesús" quien refiere la historia es coprotagonista y testigo de lo narrado. Debido a que emplea la primera persona del singular se le suele identificar con el autor del texto; pero podremos notar una distancia entre el enfoque del autor y el del personaje que narra, distancia palpable por el contraste que se puede establecer entre las conclusiones de ese personaje y algunos puntos referidos en la historia, que al igual que los enunciados directos del protagonista, ofrecen una caracterización distinta de los hechos y trazan una silueta del indígena que es distinta a la que ofrece la voz narrativa dominante. Por lo que, aunque la historia parece sencilla, exige un lector activo, capaz de confrontar el enfoque del narrador principal, diferenciado de las breves y escasas enunciaciones del protagonista, así como de la totalidad de acciones referidas en el relato, que permiten identificar el sentido que tienen en su conjunto el escrito.

El argumento del cuento se presenta como el proceso del "despertar analítico" (la toma de consciencia de su pertenencia a un grupo social marginado y el papel que sus acciones 
militantes podrían desempeñar en el reconocimiento de sus derechos como ciudadano) de un indígena llamado Jesús, y la posterior renuncia a sus ideales de reivindicación social. Renuncia relacionada con un retorno temporal al campo que realiza el protagonista indígena, mientras se encuentra trabajando como jardinero en el contexto urbano al que ha emigrado. Pues, luego de la estancia de un mes en el campo, Jesús manifiesta un cambio notable en su estado de ánimo y propósitos, abandona sus anteriores intereses y expresa el deseo de ocuparse en otra actividad laboral: la venta de pájaros, comercio ambulante al que se dedica una mujer de su mismo grupo étnico, y a quien Jesús ha conocido en algún momento que no se indica en el cuento, como tampoco se señala explícitamente la relación específica que mantiene con esta figura femenina.

En "Silueta del indio Jesús", la instancia narrativa se caracteriza por un grado notable de subjetividad; aunque también encontramos enunciaciones objetivas en las que se evitan los calificativos, las comparaciones, el discurso emotivo, y no se emplea la figuratividad poética, elementos que para Todorov serían los indicios de un enfoque subjetivo.

El narrador-personaje tiene un conocimiento parcial de lo que refiere, matiza con comentarios las informaciones que brinda, hace uso del estilo contado más que del estilo directo de los enunciados de los otros personajes; y cambia su perspectiva, evaluando siempre las acciones del protagonista a lo largo de su narración. La veracidad de sus informaciones es relativizada por esas evaluaciones y comentarios, pero su exposición es clara y suficientemente contrastada con las acciones y palabras del protagonista como para que el lector pueda sacar sus propias conclusiones y establecer distancia de lo que expresa el personaje-narrador, percibir los elementos ideológicos que se hacen manifiestos en sus palabras y detectar elementos implícitos en sus palabras y omisiones.

En un principio, las enunciaciones sirven para caracterizar positivamente al indígena, e incluso para idealizarlo, por ejemplo: cuando el coprotagonista expone lo que Jesús siente, asumiendo el rol de un narrador focalizado en la interioridad del personaje, al señalar: "Jesús no quiso contestarme. Presentía vagamente que lo podía hacer todo" (Reyes, 1989a, p. 23). También lo presenta positivamente al indicar la capacidad laboral del indígena: "Todo lo escarbó, arrancó y volvió a plantar [...]” (Reyes, 1989a, p. 23). Al describir el efecto que el trabajo de Jesús tendría en el jardín de la casa, el narrador incluso lo compara con un asceta, persa o hindú, que realiza actos prodigiosos: "[...] mostró, para el cuidado de las plantas un acierto increíble. Era capaz de hacer brotar flores bajo la mirada, como un faquir" (Reyes, 1989a, p. 23).

Esta visión idealizada que caracteriza a Jesús como capaz de hacer todo, de trabajar afanosamente, adquiere tintes lírico-poéticos cuando el narrador ofrece descripciones de la naturaleza, pues habla de flores humanizadas, animadas e identificadas con seres alados:

Y las buganvilias extendían por los muros sus mantos morados, las magnolias exhalaban su inesperado olor de limón,
las delicadas begonias rosas y azules prosperaban entre la sombra, desplegando sus alas; los rosales balanceaban sus
coronas; las mosquetas derramaban aroma de sus copitas blancas (Reyes, 1989a, p. 23).

En la caracterización del personaje indígena se descubren recreaciones de la "tópica" (Curtius, 1976) de la literatura clásica que contribuyen también a la idealización de Jesús, pues aunque no es un "niño-anciano" (Curtius, 1976, p. 123 y ss.), es presentado como un hombre que conserva una juventud perenne y es asimilado a una deidad telúrico-vegetal: "Recomenzaba su existencia después de medio siglo con la misma agilidad y flexibilidad de un muchacho [...] un paraíso de corolas y hojas [...] creadas a su deseo" (Reyes, 1989a, pp. 23-24). 
A su identificación con un "niño-anciano" también contribuyen detalles descriptivos de su gestualidad: "con un mohín verdaderamente infantil" (Reyes, 1989a, p. 23). Esto es importante, porque la "tópica" del puer senilis (niño-anciano) y su modalidad inversa (anciano-niño) -según expone Curtius- surgió como un ideal en el que se buscaba nivelar la polaridad de opuestos joven / viejo. La fusión de juventud y madurez llegó a ser considerada como un don "divino" en la literatura clásica greco-latina, tal como ocurre en Ovidio (Curtius, 1976, p. 149), y por ello también, personajes que eran caracterizados como figuras con dones sobresalientes mezclaban rasgos que referían a la madurez, unidos a otros que remitían a la fuerza de la juventud y a la inocencia de infancia, por lo que podemos afirmar que la "tópica", de muy larga tradición, involucra una perspectiva idealizadora, a la vez que es indicio del conocimiento que de la literatura clásica tenía el autor del relato (conocimiento que posteriormente Alfonso Reyes demostraría en repetidas ocasiones no solo en "La antigua retórica", "Junta de sombras", "Ifigenia cruel", "Las tres Electras del teatro ateniense", "Fastos de Maratón", también en sus traducciones de textos clásicos y en escritos tempranos como Cuestiones estéticas).

El protagonista es idealizado nuevamente cuando se le presenta de nuevo como potencia vegetal: "la cabeza del viejo aparecía a veces plácida, coronada de guías vegetales", pues como Baco, Apolo, y otras potencias "paganas", la cabeza del viejo Jesús tiene una corona de hojas, de guías vegetales y sus acciones se describen utilizando términos que lo comparan con una deidad, pues no "planta" hierbas y flores, "crea" a su deseo una frondosa vegetación.

Sin embargo, las idealizaciones señaladas no impiden al narrador-personaje exponer otras perspectivas sobre el indígena y hacer una crítica social que se centra en problemáticas que afectan al grupo étnico que Jesús representa (al referir el impedimento, cuando los indígenas visitaban la ciudad, de hacer el uso de una prenda de vestir tradicional como lo era el calzón de manta, pues portarlo llegaba a ser motivo de detención por parte de los gendarmes; la carencia de un sistema educativo que les permitiera llegar a conocer sus derechos, la necesidad de recurrir a recomendaciones de los habitantes de la ciudad al buscar empleo y la servidumbre a la que su empleo los destinaban), a la vez que destaca aspectos de su intelecto, de su circunstancia vital y la forma negativa en que el contexto lo afectaba:

[...] sabía deletrear y, con sorprendente facilidad, acabó por aprender a leer [...] Comenzó a contaminarse con el aire de la ciudad. La inquietud reinante se fue apoderando de su alma. Él, que conocía de cerca los errores del régimen, no tuvo que esforzarse mucho para comprender las doctrinas revolucionarias [...] (Reyes, 1989a, p. 24).

Como en muchas obras de la época ("La venganza de Milord” y "La novela del tranvía" de Manuel Gutiérrez Nájera; “Sepultados” de Salvador Quevedo y Zubieta; La parcela de López Portillo y Rojas; La rumba de Ángel del Campo; El bachiller de Amado Nervo; Los parientes ricos de Rafael Delgado; Claudio Orozco de Rubén M. Campos; Santa de Federico Gamboa, así como La Malhora o El desquite de Mariano Azuela), podemos observar aquí la presencia de una dicotomía en la que se oponen campo y ciudad (fenómeno que Gutiérrez Girardot ha estudiado en el apartado titulado "Secularización, vida urbana, sustitutos de la religión" de su obra de 1987), lo que favorece una visión negativa de la ciudad, pero unida también a una crítica política que busca reivindicar al indígena, no al indígena legendario y heroico, sino al que es contemporáneo al relato, al sujeto que emigra del pueblo a la ciudad, es autodidacta, se informa sobre análisis marxista y ha sufrido en carne propia los "errores del régimen".

La distancia temporal, entre el momento en que se ubica el inicio de los hechos referidos y su final puede inferirse, si consideramos las distintas indicaciones que se ofrecen en el texto, 
pues aunque inicialmente las indicaciones son imprecisas: "Vino el día en que el indio Jesús, a quien yo encontré en no sé qué pueblo, se me presentara en México" (Reyes, 1989a, p. 23), más adelante -aunque sin ofrecer fechas- hay datos que indican un lapso que abarca varios meses y que inicia antes de que estallara la lucha armada revolucionaria en México, prolongándose hasta un poco después de que la Revolución fuera un acontecimiento en desarrollo: "con algunas noticias alarmantes: la revolución había comenzado" (Reyes, 1989a, p. 26). Es decir, que el relato fue escrito y sitúa su acción varios años antes de que la Revolución Mexicana se consumara, y más de una década antes que el gobierno postrevolucionario asumiera una política indigenista institucional, difundida a través del arte y la literatura que como sabemos:

\footnotetext{
puso en juego dos fuerzas de contrario signo; la primera llevó a la idealización del pasado indígena como evidente reacción contra el extranjerismo [...] y como punto de apoyo para fundamentar un nacionalismo que diferenciara a México en el concierto de las naciones. La segunda [...] impulsó una deliberada tendencia hacia la modernización (Beals, 1951, citado en Aguirre y Pozas, 1954, pp. 20-21).
}

A esto se añade que: "La utopía posrevolucionaria sería interpretada de muchas maneras, pero nunca en ventaja para los indígenas" (Korsbaek y Samano Rentería, 2007, p. 201). Para Gamio, el ideal era el mestizaje; para Vasconcelos, la "raza cósmica", una suerte de indígenas identificados con los antiguos griegos, y para Sáenz, la asimilación de las culturas indígenas con el propósito de "uniformizarlas" (Korsbaek y Samano Rentería, 2007, p. 201).

Aunque el relato es retrospectivo, en algunos enunciados se emplea el presente, lo que actualiza el pasado, sobre todo en ciertos comentarios sobre los indígenas. Los enunciados en los que emplea el presente atañen a interrogantes que manifiestan un desconocimiento importante de Jesús por parte del narrador coprotagonista: “¿Pero tú qué sabes hacer, Jesús?” (Reyes, 1989a, p. 23); aunque también se emplea el presente en afirmaciones generales admirativas hacia el indígena: “QQué bien armonizan con la flor, la sonrisa y el sollozo del indio!” (Reyes, 1989a, p. 24), o en afirmaciones caracterizadoras que luego se volvieron lugares comunes: "Porque el indio mexicano se roza mucho con la muerte" (Reyes, 1989a, p. 25). También encontramos el presente en enunciados en los que se describe el desconocimiento por parte de los personajes citadinos de los motivos de Jesús: "Todos adivinamos" (Reyes, 1989a, p. 25), frase significativa por indicar que el pasado, las circunstancias y motivaciones de las acciones de Jesús, las razones que las impulsan, son desconocidas para todos, incluso para el narrador-personaje. El presente también figura en enunciados que contienen la percepción del indígena hacia sí mismo: “iSi estoy retejuerte!” (Reyes, 1989a, p. 26).

Hay en el cuento un pasaje que es referido mediante una mezcla del estilo indirecto y directo, en el que se conservan los contenidos y matices semánticos de las réplicas originales de cada personaje, mediante frases que introducen y explican una oración traspuesta en el relato del narrador (Todorov, 2004, pp. 82-83). En este pasaje se emplea el presente, aunque se trata de un hecho pretérito, señalado por el narrador como algo que él deseaba contar; a diferencia de la anécdota del siglo XVI sobre Juan Cárdenas en su encuentro con los indígenas de la entonces Nueva España, aludida previamente por el narrador coprotagonista, pues el narrador indica expresamente que él no desea hablar sobre los indígenas históricos, vistos a través de los ojos de un médico sevillano, radicado en Nueva España desde su adolescencia, y caracterizados en la Primera parte de los problemas y secretos maravillosos de las Indias (1591); él desea hablar de un indígena que le es contemporáneo y quien le hace una solicitud específica, le pide un obsequio, demostrando que confía en él: 
Jesús se puso de pronto un tanto solemne y me pidió un obsequio:

-Quiero -me dijo- que, si no le hace malobra, me regale el niño una Carta Magna.

-¿Una Carta Magna, Jesús? ¿Un ejemplar de la Constitución? ¿Y tú para que lo quieres?

-Pa conocer lo Derecho del Hombre. Yo creo en la libertad, no agraviando a lo presente, niño (Reyes, 1989a, p. 25).

Estos enunciados proporcionan informaciones valiosas sobre las perspectivas de los dos personajes, aunque de manera sintética, y es revelador que al narrador citadino le extrañe que Jesús le solicite un ejemplar de la Constitución y lo cuestione sobre cuál es la función que va a darle al regalo solicitado; del mismo modo en que es demostrativo que Jesús, luego de declarar su creencia en la libertad, se disculpe con quien ha sido su benefactor (al auxiliarlo a conseguir trabajo como jardinero en casa de un familiar), pues lo reconoce como un miembro de un grupo social al que podrían "agraviar" sus convicciones y sus deseos. Se representa aquí literariamente una tensión social, una lucha de clases tamizada por los afectos, pues se trata del dialogo que un indígena -que está interesado en conocer las leyes y manifiesta su voluntad por continuar aprendiendo y militar políticamente en actividades organizadas- sostiene con alguien en quien confía lo suficiente para pedirle ayuda, pese a que no es miembro de su mismo grupo étnico, ni económico, sino de un grupo al que él está subordinado. El personaje de Jesús no es una figura plana que carezca de distintas aristas, se presenta como un personaje en conflicto interno que aunque confía en el narrador, está consciente de las diferencias de valores y aspiraciones existentes entre él y su auxiliar, sabe que forman parte de grupos sociales distintos y confrontados. El indígena, además, se encuentra en una situación tal que debe pedir como obsequio un ejemplar de las leyes que rigen su país para conocerlas y debe pedírselas a quien podría "agraviarle" su postura social. El autor del relato representa así las contradicciones derivadas de diferencias étnicas, socioeconómicas e ideológicas desde un enfoque humanista, alejado de maniqueísmos, y por ello no ignora sugerir algunas de las tensiones internas generadas por la toma de conciencia social del personaje indígena, frente a la gratitud que este experimenta hacia su benefactor. Relaciones afectivas, deseos de reivindicación y diferencias de clases sociales que luego son descritas desde la perspectiva exclusiva del narrador-coprotagonista:

\footnotetext{
[...] Jesús se había afiliado en el partido de la revolución y asistía a no sé qué sesiones. Yo vi brillar en su cara un fuego extraño. Comenzó a usar de reticencias [...] Éramos para él familia de privilegiados, contaminada de los pecados del poder. A él no se le embaucaba, no. Harto sabía él que no estábamos de acuerdo con los otros poderosos, creía en los nuevos [...]. A mí, sin embargo, "me tenía ley", como él decía, y estoy seguro de que se hubiera dejado matar por mí [...] (Reyes, 1989a, p. 24).
}

La cita permite notar que el narrador también confía en Jesús. Se trata de dos individuos inmersos en una estructura de poder que interfiere en los vínculos afectivos que ellos pudieran desarrollar. Además, el análisis de los registros discursivos permite identificar la presencia de enunciados propios de un discurso religioso que figuran entremezclados con otros que provienen de un discurso militante de izquierda y que ilustran un proceso de secularización problemática (Gutiérrez, 2004, p. 80) en el protagonista, pues en sus enunciaciones -aunque expresadas en un estilo contado por el narrador- los abusos de poder son identificados con "pecados", manifestando la pervivencia de las creencias religiosas de quien milita en un partido popular de izquierda. De modo que Jesús queda caracterizado como un personaje en él que se manifiesta una problemática derivada de una mezcla de creencias distintas, pero también de convicciones sociales y afectos en conflicto. El indígena es también considerado aquí como un individuo de lealtad inquebrantable, que busca superar 
su condición socio-cultural, además de demostrar una capacidad para analizar la información política que le brindan y contrastarla con su experiencia, siendo eficiente en distinguir entre las distintas posturas de los grupos sociales con los que está en contacto. En todo momento, esta caracterización es realizada por el narrador citadino, que aquí describe todavía desde un enfoque valorativo al protagonista y habla por él y con él.

Sin embargo, la toma de conciencia social y política de Jesús se verá interrumpida en el relato, y en este punto conviene precisar la estrategia utilizada por Reyes para sugerir las razones que operan en el cambio final que afecta al personaje y que el lector debe "descubrir" por sí mismo, pues el narrador-personaje señala que no las "alcanza a comprender". Pese a que nos ha indicado que Jesús ha viajado al campo y a su regreso se ha mostrado pensativo, inactivo, sus ideas se han transformado, abandonando el gusto por cultivar flores y por la lucha social. Luego señala que el indígena está en compañía de una mujer y ha decidido dedicarse a la misma actividad que ella, por lo que va a irse de la ciudad con ella. Esto permite al lector suponer que Jesús está ligado a esa figura femenina, respecto a la que asume una responsabilidad o un afecto que está por encima de sus ideales sociales, de su previa actitud crítica y militante. En cambio, el narrador-personaje señalará exclusivamente que se ha producido una alteración que para él implica una incógnita, por lo que saca conclusiones que lo llevan a desvalorar a Jesús y su actitud "[...] cómo fue que Jesús, a punto ya de convertirse en animal consciente y político, se derrumbó otra vez por la escala antropológica, y prefirió sentarse en la calle de la vida, a verla pasar sin entenderla" (Reyes, 1989a, p. 26).

Si bien se pueden advertir en la cita huellas de una concepción propia del evolucionismo cultural, es también indudable que el narrador-personaje considera que la conciencia política constituye un rasgo definitorio de un estado superior humano y que la negativa a comprender la realidad social es considerada por él como algo que degrada al individuo. Esta perspectiva del narrador citadino elimina una visión paternalista y expresa una visión del narrador personaje en la que se identifica una doble responsabilidad en la situación marginal denunciada al identificar como sus causales, tanto las políticas gubernamentales del Porfiriato hacia los indígenas, como la renuncia voluntaria del sujeto marginado que acepta que la situación injusta siga, al alejarse y abandonar su lucha. Una determinación que queda connotada para el narrador de tintes evasionistas, porque él no ve en la vida elegida por el indígena un progreso civilizador, ni una integración a la vida urbana, a la conciencia política y social; por el contrario: identifica la vida marginal que elige Jesús con un derrumbe en la escala antropológica y con una renuncia a comprender la vida, lo que lo lleva a desvalorarlo, sin darse cuenta de las causas profundas que mueven al protagonista.

Sin embargo, la perspectiva del narrador y la del autor no son del todo coincidentes, porque, depositando gran confianza en su lector, el autor del cuento ofrece un argumento de "hechos" que desmienten la conclusión hecha por el narrador, y esos "hechos" explican parcialmente la aparente "resignación" de Jesús. Lo presentan como un protagonista que responde a una responsabilidad o un afecto hacia una mujer indígena cuyo destino desea o debe compartir; determinación que lo lleva a renunciar a la lucha por su reivindicación social, a su proceso de aprendizaje y a la situación laboral que disfruta. Además, asumir estas renuncias no es fácil para él, como lo indica el cambio emocional que opera a su regreso del campo.

De manera que en la narración cobran un peso semántico equivalente: lo que es explícito y lo que solo se sugiere, lo que queda en el implícito de los hechos y en las acciones. 
Fenómeno análogo al que tiene lugar en las artes gráficas en la representación de un personaje mediante una silueta, en la que los bordes de la figura sugieren el gesto somático y fisonómico del mismo, las características detalladas que se han omitido al emplear la síntesis figurativa.

La instancia narrativa del cuento se caracteriza por los rasgos y modalidades manifiestos en las voces que relatan, por lo que resulta importante destacar otros aspectos que esta voz dominante ofrece de Jesús, pues en las palabras del narrador-coprotagonista se emplean una serie de identificaciones que involucran campos semánticos de la violencia y la muerte, pero también del espectáculo, la dualidad del ser y la religión católica, en enunciados que mitifican $\mathrm{u}$ ofrecen contradictorias perspectivas generalizadoras del indígena, señalando una alteridad y una dualidad proyectada en la figura del indígena. Así, por ejemplo, el narrador destaca sobre Jesús: "su elástico paso de danzante", sus piernas "de resorte hechas para el combate y el salto", lo concibe como un ser "capaz de reñir y matar sin odio: por obediencia, o por azar", como miembro de un grupo étnico que "se roza mucho con la muerte", identificándolo con actividades un tanto estereotipadas para representar a los indígenas mexicanos (danzantes y guerreros), personajes dóciles (obedientes a una orden o al "destino"), en estrecha proximidad con la muerte, y que poseen tradiciones de comunicación particulares. Personajes definidos también como cómicos y no arraigados: "Indio retórico", dueño de un "oído finísimo", "bufón errabundo". Los indígenas son para el narrador- coprotagonista poseedores de una dualidad antitética: "Indio almibarado y, a la vez, temible". El nombre mismo del personaje implica, además, una referencia a una tradición religiosa católica, lo que indica su relación con una cultura sincrética y el indígena vuelve a ser mitificado por el narrador que lo hace descendiente de Juan Diego, vinculándolo así con una anécdota asociada a la identidad nacional de varias formas ${ }^{1}$ y que implica una relación entre el indígena y las flores "milagrosas": "Jesús, como su remoto abuelo Juan Diego, dejaba caer de la tilma -cualquier día del año- un paraíso de corolas y hojas" (Reyes, 1989a, p. 24).

Los detalles previos y los inmediatamente antes señalados muestran enfoques distintos al observar y representar al indígena, por una parte idealizado, mitificado, pero también concebido por el narrador-personaje como un ser singular (creador admirable, danzante, guerrero temible y a la vez ser dócil, capaz de matar sin odio, cómico, vagabundo, "retórico", de apariencia servil, que se "derrumba en la escala biológica" sin motivo aparente y que prefiere el aislamiento a la integración social). En tanto la mujer indígena es caracterizada por el narrador-personaje como personaje negativo y calificada como "mezquina". Caracterización contrapuesta a aquella que deriva de las palabras y acciones de Jesús. Palabras y acciones que también lo presentan a él mismo como un ser humano que sabe de agricultura, es autodidacta, tiene consciencia política y sentido crítico, es capaz de separar sus afectos y sus ideales sociales, pero es capaz también de anteponer la responsabilidad y/o el afecto hacia una mujer, a su lucha social, a su condición laboral "privilegiada"; una mujer de su mismo grupo étnico, que habla su misma lengua, por lo que la identificación entre Jesús y la mujer desempeña un lugar importante en el texto y en la decisión de Jesús por seguir una vida sencilla en la marginalidad $^{1}$.

Lo anterior significa que de manera dominante -aunque no exclusiva- una visión mitificada y otra humanista sobre el indígena se confrontan en el relato para definir su

1 Por el papel que se le otorgó a la imagen de la Virgen de Guadalupe en el arranque de las luchas por la Independencia, entre otros puntos. 
identidad étnica desde dos enfoques: el del narrador y el que el lector adquiere a partir de todo lo que le ha sido expuesto y sugerido en el relato, que le permite cuestionar los estereotipos, idealizaciones o certezas del narrador- coprotagonista.

No deja de ser significativo que varios de los rasgos que figuran en las palabras del narrador personaje sobre el indígena (la dualidad, la importancia dada al lenguaje, la vinculación con la muerte y con lo cómico o festivo, con el espectáculo, el aislamiento, la vinculación del protagonista a la tradición sobre la Virgen de Guadalupe, la visión negativa de la mujer indígena) fueran repetidos - con algunas variantes- y generalizados, para caracterizar la identidad del mexicano en obras como El laberinto de la soledad (Paz, 1950), pero no solo en ese ensayo literario y por esto Ilán Stavans señalaría en su estudio sobre el tema:

[...] a través de la Virgen de Guadalupe y de la Malinche [...] la fiesta, la atracción a la muerte y la soledad existencial [...] la hiperestesia de los símbolos religiosos, los intelectuales y artistas que han seguido la huella de Guerrero, Chávez y su séquito deducen, o creen deducir, quién es el mexicano [...] (Stavans, 1993, pp.11-12).

Sin embargo, a esta caracterización del indígena, afín a otras que se han hecho del mexicano, realizada por el narrador citadino, se opone la otra caracterización que deriva de las acciones del protagonista y de las palabras que éste expresa directamente, que conforman un conjunto de signos que manifiestan que el indígena "ése que está allá afuera, el de los suspiros, las lágrimas las alegrías y los secretos, es inaprensible, esquivo" (Stavans, 1993, p. 129) es mucho más complejo que cualquier representación que de él pudiera hacer quien no lo conoce realmente, aunque desee ayudarlo, admire aspectos de su identidad, lo idealice; o lo desvalore sin comprenderlo. La cita de Stavans nos permite destacar que en el relato de Reyes se expone una visión sobre el indígena que muchos intelectuales mexicanos (consultar Stavans, 1993), incluso de la segunda mitad del siglo XX, no llegaron a tener, al lado de esa otra que ellos sostuvieron y extrapolaron al ser nacional.

Las estrategias narrativas de Reyes no son evidentes, se van descubriendo en el análisis de los detalles, por ejemplo, dentro del cuento se relata una anécdota en la que Jesús tiene un encuentro con un carretero y que, al igual que el episodio previo al final del relato, nos muestra aspectos del personaje que no solo contribuyen a su caracterización, también exponen una complejidad en él, que al narrador-personaje del cuento se le escapa, debido a que su conocimiento de Jesús es limitado y a que su propia ideología le impide considerar la complejidad del indígena:

\footnotetext{
Yo los sorprendí en el momento en que Jesús asió el sombrero como una rodela, dio hacia atrás un salto de gallo, y al mismo tiempo sacó de la cintura el cuchillo -el inseparable "belduque"-con una elegancia de saltarín de teatro. Yo lo oí decir, con una voz fruiciosa y cálida:

-¡Hora sí, vamos a morirnos los dos!

[...] adivinamos que aquellos dos hombres, cada vez que se encontraran de nuevo, caerían en la tentación de hacer el mutuo servicio de matarse (Reyes, 1989a, p. 25).
}

Jesús tiene una historia que le es desconocida al narrador, que él solo "adivina", lo cual señala la distancia que media entre él y el protagonista. El narrador únicamente supone quién es Jesús, aunque nos "habla por él", pues son contadas las ocasiones en que figuran las palabras literales del indígena: pero este narrador del cuento, a diferencia de lo que señala Todorov en otra de sus obras, no solo habla del indígena sin hablar con él (1987, p. 143); nos refiere las conversaciones que sostiene con el indígena. Este fenómeno textual es importante 
si consideramos que: "sólo cuando hablo con el otro (no dándole órdenes, sino emprendiendo un diálogo con él) le reconozco una calidad de sujeto, comparable con el sujeto que yo soy" (Todorov, 1987, p. 143), por lo que podemos decir que en el relato, el narrador llega en algunos momentos a reconocer la calidad de Jesús como sujeto comparable a él, y es justamente cuando el dialogo se rompe, se anula, que su perspectiva y valoración del protagonista cambia radicalmente.

En la mayor parte del texto se hace una reivindicación explícita del indígena y se busca comprenderlo y denunciar algunas situaciones que lo afectan desde la perspectiva de ese narrador- personaje no indígena, cuya comprensión limitada y conocimiento no profundo del protagonista es reconocida dentro del relato por el propio narrador del cuento. Es decir, se representa en el texto de ficción conscientemente, explícitamente, una perspectiva parcial y externa a la cultura del protagonista, desde la cual se le describe, a modo de indicaciones que están dirigidas al lector. El narrador, además, proporciona una serie de datos sobre el indígena que desde su enfoque no resultan significantes, aunque se trata de acciones y no de rasgos atribuidos (cualidades y "defectos", considerados como tales por el narrador-personaje). Esos otros datos sobre las acciones del indígena permiten que el lector forme una opinión y tenga un conocimiento más amplio, no se quede con la evaluación y juicio conclusivo-desvalorativo final expuesto por el narrador coprotagonista que expresa: "Nunca entenderé...".

En el relato de Alfonso Reyes se están ofreciendo las caracterizaciones de dos personajes distintos: un protagonista indígena y un narrador citadino, mestizo o blanco, que evalúa y caracteriza al indígena a partir de un conocimiento parcial y "externo" que tiene de aquel. Al mismo tiempo que el autor ofrece informaciones, a través de ambos personajes, que le permiten al lector evaluarlos e identificar las dos ideologías y grupos sociales que cada uno de ellos representa. Por lo que encontramos en el cuento trazados ideológicos diferenciados, al tratarse de dos sujetos que no solo representan dos tradiciones culturales, también porque forman parte de grupos sociales distintos, uno de ellos subordinado al otro, dentro del contexto social que en el cuento se representa.

El narrador no es indígena, forma parte de una familia con un nivel económico que le permite contar con un empleado a su servicio, es un sujeto educado que ha estado en contacto con las teorías del evolucionismo socio-cultural (Herbert Spencer, Lewis Henry Morgan, Edward Burnett Tylor) y con las tradiciones religiosas del país, y que aunque denuncia los problemas del indígena, también lo juzga, desistiendo de conocerlo a profundidad. El indígena se caracteriza a sí mismo por sus acciones y breves palabras, y caracteriza, a su vez, al narrador, a sus patrones y a los líderes del partido en que milita temporalmente. Porque pese a que la instancia narrativa se distingue por una voz que domina la narración, el escritor ha ingeniado la forma de introducir indicios y datos sobre la perspectiva del indígena de forma simulada: él sabe que sus ideales sociales son diferentes a los del coprotagonista, confía en él, pero no pierde de vista que puede sentirse agraviado por su deseo de conocimiento y superación, no le explica sus razones, no le habla de sus sentimientos ni sus responsabilidades. 


\title{
3. Indigenismo, modernismo
}

El cuento, escrito en $1910^{2}$, en pleno apogeo del modernismo hispanoamericano, manifiesta en algunas descripciones, particularmente de las flores, puntos de contacto con los tópicos modernistas, elementos sobre los cuales ha llamado la atención James W. Robb, aunque él los asocia al mundo indígena y no a tópicos del modernismo, cuando afirma:

\begin{abstract}
"capaz de hacer brotar flores bajo su mirada, como un faquir", o sea como un mago oriental. Y nos inunda una visión maravillosa, multicolor y multisensorial, una explosión de exuberancia creadora, de flores y de plantas que se multiplican: "En la fuente hizo flotar unas misteriosas flores acuáticas..." Jesús en medio de las flores se identifica con las celebraciones florales [...]: señales de sincretismo miticoreligioso que caracteriza el mundo indígena mexicano (Robb, 1991, pp. 139-140).
\end{abstract}

La presencia de tópicos modernistas ("exotismo oriental" manifiesto por la referencia al faquir y a los nenúfares, a "misteriosas flores acuáticas"3; sincretismo mítico-religioso que involucra principalmente la tradición católica y la indígena, propio de una tradición mestiza y no ausente en la tradición indígena afectada por un proceso de catequización e hispanización constante en las ciudades y pueblos mestizos; énfasis en lo sensorial, idealización de la naturaleza), son elementos que debieron llamar la atención de Robb sobre las relaciones entre el cuento de Reyes y la literatura modernista, en pleno auge en la época. Si bien, estos fenómenos no le impiden a Reyes recuperar también lo localista ${ }^{4}$ y el habla coloquial popular ${ }^{5}$, porque el tratamiento de lo regionalista y de lo autóctono tampoco fue ajeno al modernismo: “[...] los primeros textos del siglo pasado brotaron del innegable influjo modernista; sin embargo, a veces en un mismo autor, por ejemplo en Valdelomar, las tendencias románticas, regionalistas y modernista se mezclan" (Zavaleta y Jaime, 2003, p. 5), como tampoco el modernismo fue ajeno a la presencia de elementos que correspondían a una estética naturalista (Varas, 1996, pp. 132-157; Jiménez, 1992, pp. 16-17). En el cuento de Reyes se hace presente en algunos párrafos que incluyen el enfoque positivista mediante el análisis de la psicología social de la época:

2 Año en que inició la Revolución Mexicana cuyo conflicto armado se prolongó, pues los investigadores más conservadores la consideran consumada en 1914, en tanto otros hasta 1920. Durante todo el siglo XIX la política dirigida hacia la población se perfilaba como una política de erradicación de los indígenas, mediante diversas estrategias, entre ellas el mestizaje, para "así blanquear al país", pero también esas estrategias implicaron el genocidio. La Revolución Mexicana no fue una revolución de los indígenas, a ella siguió un indigenismo institucional, "que empieza en el período posrevolucionario, para adquirir fuerza con el congreso en Pátzcuaro en 1940 y con la creación del Instituto Indigenista Interamericano a nivel continental y del Instituto Nacional Indigenista en México (1948)" (Korsbaek y Sámano, 2007, pp. 195-224).

3 Reyes se había ocupado de temas "exóticos" en "Visiones del Japón", contenido en el tomo IV de sus Obras completas (1956) e incluso había escrito en 1913 un hai-kai que publicaría seis años después. En su cuento "El samurái", un personaje es comparado positivamente con un guerrero japonés, al derrotar al narrador de la historia. En "La cena" se hace referencia a máscaras japonesas que son parte de un decorado y las torres de los relojes se equiparan con esfinges en la calzada de algún templo egipcio.

4 "las fiestas del Viernes de Dolores que celebraban los indios en canoas y chalupas del Canal de la Viga" (Reyes, 1989a, p. 24), la práctica del comercio ambulante de pájaros, cuyos vendedores se desplazaban: "trotando con el huacal a la espalda" (Reyes, 1989a, p. 26) por ciudades y pueblos, referencias a las costumbres de comunicación de ciertos grupos: "Los indios [...] charlan en voz baja y dialogan así, en su lengua" (Reyes, 1989a, p. 26), etc.

5 “y decía: que ansina no se podía trabajar" (Reyes, 1989a, p. 23), "me tenía ley” (Reyes, 1989a, p. 24), “¡Hora si, vamos a morirnos los dos!” (Reyes, 1989a, p. 25), etc. 
La india flaca y mezquina tenía la misma cara atónita [...] Estos dos indios venían a la ciudad -estoy convencidomás que a vender pollos, a sentirse sumergidos en el misterio de una civilización que no alcanzan; a anonadarse, a aturdirse, a buscar un éxtasis de exotismo y pasmo (Reyes, 1989a, p. 26).

Una perspectiva que sirve para ofrecer caracterizaciones "negativas" del indígena, visto desde un plano de superioridad en el relato del narrador-coprotagonista: "disgustaba a la gente con sus apariencias de cortesía servil” (Reyes, 1989a, p. 25).

Reyes se negó a ser adscrito al modernismo, sin embargo, Mario Martín identificará a Reyes como un modernista de la tercera etapa del movimiento (Martín, 1976, p. 104), y aunque Bella Jozef (1991) lo clasifica en lo que él denomina postmodernismo, José Miguel Oviedo (2001, p. 11) y Alonso de Toro (1990, pp. 13-14) cuestionan seriamente la definición de este término. Francisco Albizúrez (1988), por su parte, distingue entre modernismo y postmodernismo, no a partir de autores, pues considera que muchos autores modernistas se verían afectados por cambios a lo largo del tiempo en sus propias producciones, y considera postmodernistas solo a quienes experimentaron más allá de sus primeras propuestas. Nosotros no pretendemos clasificar a Reyes sino identificar las relaciones que su obra guarda con algunas tendencias literarias contemporáneas a la producción de sus obras, como parte de su contextualización en la Historia de la Literatura Mexicana e Hispanoamericana, por ello, debemos destacar que las relaciones de Reyes con el modernismo abarcan diversos aspectos. En el mismo año en que Reyes escribe el cuento estudiado, da a conocer su ensayo sobre Los poemas rústicos de Manuel José Othón en el que no solo identifica y admira algunos de los elementos con que se suele caracterizar el modernismo (el énfasis en lo sensorial, sobre todo lo visual, mediante los "rasgos de color" y las cualidades lumínicas de lo descrito, el énfasis en lo sonoro mediante la evocación de lo auditivo, el uso de onomatopeyas, aliteraciones, ritmos, la presencia de cierto "misticismo", el uso de materiales mitológicos, el sincretismo religioso, la recuperación de tradiciones literarias que remitían a distintos estilos, la atención puesta en los elementos formales, la importancia que cobraba la naturaleza, etc.), sino que también elogia "la elegancia de la sintaxis" de Rubén Darío (Reyes, 1955, p. 184). Además, en marzo de 1906, se había dado a conocer Savia Moderna "Revista Mensual de Arte". Esta revista estaba bajo la dirección de Alfonso Cravioto y Luis Castillo Ledón, contaba con treinta cuatro redactores y -según palabras del propio Reyes, quien formó parte de la revista- era una publicación que: "No sólo en el nombre, en el material mismo prolongaba a la Revista Moderna" (Reyes, 1997, p. 202). Alfonso Reyes se encargaría después de la publicación de las obras completas de Amado Nervo, XXIX volúmenes, a partir de 1920.

Otros elementos presentes en el cuento estudiado se vuelven importantes cuando consideramos que Antonio Cornejo Polar, en uno de sus trabajos sobre el indigenismo (Cornejo, 1997, p. 456), llama la atención sobre varios aspectos señalados por Ángel Rama respecto a la obra de Arguedas:

Las formas originarias que la cultura indígena ponía a disposición del escritor eran la canción y el cuento folklórico. Las que proponía la cultura dominante eran la novela y el cuento dentro de los modelos establecidos bajo la doble advocación regionalista y social que [...] se filiaba en el relato realista de la segunda mitad del siglo XIX europeo [...] Arguedas [...] en la opción genérica, se decide en favor de aquellas formas que rigen la cultura occidental. Pero, a partir de tal elección, observaremos que promueve un tratamiento interno de esas formas que introduce notorias modificaciones (Rama, 1976, p. 27).

Alfonso Reyes también ha elegido un modelo genérico: el cuento, que forma parte de las formas que rigen la cultura occidental, y ha introducido notables modificaciones, 
aunque estas modificaciones no provienen dominantemente de elementos de las culturas autóctonas (indígenas), sino de las culturas "mestizas" (aunque también autóctonas) nacionales, pues la mayoría de las ocasiones quien "habla" en el relato no es un indígena.

Reyes no presenta al indígena en un universo armónico en el que "no caben las contradicciones", como se ha generalizado al abordar el tema del indigenismo en la época y en el que los conflictos solo "provienen del exterior", o son originados por el "hombre blanco" (Maldonado, 1996, p. 47). Reyes ha presentado un contexto urbano en el que el indígena es marginalizado, pero también en el que tiene la oportunidad, mediante su esfuerzo, y pese a las políticas gubernamentales, de desarrollar una conciencia social apoyado por la lucha política de otros miembros de la comunidad marginada que se han organizado. Los conflictos en la vida de Jesús son externos e internos, lo que se representa a través del enfrentamiento de Jesús con un trabajador de su misma condición social y en los cambios que lo afectan luego de su estancia en el campo. El contexto rural del cual procede el personaje tampoco es un universo idealizado (Maldonado, 1996), en este contexto el indígena no tiene trabajo, por ello emigra a la ciudad para trabajar, "resuelto [...] a servir a la capital" (Reyes, 1989a, p. 23). Cuando Jesús permanece en el campo opera en él una transformación que se describe mediante un símil significativo, pues todo el vigor del indígena parecía haberse sumido "como agua en un suelo árido" (Reyes, 1989a, p. 25), lo que connota ese espacio rural de aspectos negativos para el indígena, tan negativos como los de la zona urbana. Además, aunque Jesús manifiesta su deseo de volver a un contexto rural, no pretende volver al pueblo en el que lo encontró el narrador; se dedicará a vender pollos por los caminos polvosos y manifiesta también querer irse al "cerro". Todo esto señala que Jesús no es tanto un indígena dividido entre dos mundos, o que no logra adaptarse a la vida citadina; Jesús es un personaje desprovisto de un lugar para $\mathrm{sí}^{6}$, que ha determinado buscar en un espacio alejado del pueblo y de la ciudad, el lugar para vivir en compañía de otro ser humano que habla su misma lengua y forma parte de su grupo étnico. Este punto constituye una denuncia de la forma en que el indígena ha sido desposeído de su propio territorio y cultura.

La perspectiva desde la que se describe al personaje y el "mundo indígena" no excluye contradicciones en el texto, pero también da lugar a un enfoque de solidaridad y humanización, a un enfoque en el que el indígena se caracteriza, no por lo que otros expresan de él sino por lo que él hace y lo que deja entrever en sus expresiones "directas", literales, aunque escasas, lo que contradice también algunas de las caracterizaciones que de él ofrece el narrador coprotagonista: "daba a sus frases más palabras de las que hacía falta, cargándolas de expresiones ociosas" (Reyes, 1989a, p. 25), facultando al lector a cuestionar la forma como interpreta a Jesús.

En el texto se exponen huellas ideológicas que caracterizan también al coprotagonistanarrador, su ideología, condición social, su forma de interpretar a quienes lo rodean y conviven con él, pues idealiza al indígena cuando lo relaciona con la naturaleza, la idealización se atenúa cuando Jesús se vuelve un sujeto activo política y cívicamente, pero al generalizar sobre su grupo étnico lo mitifica y arquetipifica (como guerrero, bufón, bailarín, como figura que representa

David A. Brading y María Urquidi (1989, p. 268) han señalado que la Reforma había eliminado la personalidad jurídica de los pueblos indígenas, lo que propició que muchas comunidades se vieran indefensas ante la expansión de las haciendas y acabarán perdiendo progresivamente sus tierras. Esto puede resultar sorprendente si se considera que dicha Reforma había sido promovida por Benito Juárez, un presidente de origen indígena. 
una alteridad), y lo desvalora cuando su actuar no corresponde a las concepciones que él tiene, cuando el indígena decide algo distinto a su conceptualización de lo que debería ser el destino de ese indígena. Es incapaz de comprender los conflictos, necesidades y valores de quien es finalmente para él, un ser ajeno, distinto y "propio" de otra condición social. Lo que se significa que el narrador-coprotagonista es también evaluado en el relato y es representado de manera que el lector puede hacer sobre él una crítica.

A ese enfoque del coprotagonista se confronta el que deriva de las acciones y anhelos de Jesús, uno de los cuales es la libertad. Por lo que encontramos en este cuento la ilustración de algunas de las contradicciones en las que incurre un citadino (mestizo o blanco) de cierto estatus social y educado, al caracterizar y evaluar a un indígena, al que en algún momento le llega a tener afecto, al que ayuda a conseguir trabajo, pero al que realmente no conoce, ni busca conocer. Sus opiniones y grado de conocimiento del protagonista no son sino un esbozo que no le permite intuir o explicar lo que ese indígena hace y desea, las problemáticas sociales e individuales que sufre, las necesidades y responsabilidades humanas que asume o se ve obligado moralmente a asumir.

Debemos aclarar que aunque el tema del indio o la presencia de personajes indígenas en una obra, parecerían llegar a ser considerados como elementos suficientes para hablar de indigenismo para algunos estudiosos (Bautista (2009), Mamour (2007) y Warman (1978, párr. 5) quien señala que: "Muchos consideran Las cartas de Relación escritas por Hernán Cortés como la primera literatura indigenista producida en México"); aquí nos adscribimos a una caracterización del indigenismo literario en un sentido más acotado, de modo que consideramos solo aquellas obras literarias en las que el indígena es protagonista de la historia y en las que se aborda, de manera no tangencial, algunas de las problemáticas que como integrante de un grupo étnico específico lo afectan o lo han afectado, a lo que se debe añadir una perspectiva que busca la comprensión y revaloración del indígena y su cultura. La definición del indigenismo que Favre propone es muy amplia: "el indigenismo en América Latina es, para empezar, una corriente de opinión favorable a los indios" (Favre, 1998, p. 7). Exige una acotación, la concepción del indigenismo literario como una representación verbal-conceptual que producen escritores no indígenas. Lo que nos permite distinguir también el indigenismo literario de las concepciones y políticas indigenistas, concepto que corresponde a la definición que ofrece Juan Villoro: "aquel conjunto de concepciones teóricas y de procesos conciénciales que, a lo largo de las épocas, han manifestado a lo indígena" (1950, p. 9) en modalidades pre-institucionales e institucionales; y diferenciar también otros conceptos afines, desarrollados dentro y fuera del ámbito literario con los que en más de una ocasión se le confunde, como los de indigenismo cultural (Torres, 2009, p. 334) ${ }^{7}$, indianismo (Torres, 2009, p. 333) ${ }^{8}$, textos de Descubrimiento y Conquista, narrativa etnográfica (García y Maeztu, 1999, pp. 113-118) ${ }^{9}$ e incluso literatura indígena.

7 "El profesor Lancelot Cowie, en su libro titulado El indio en la narrativa contemporánea de México y Guatemala (Instituto Nacional Indigenista, 1976) acuñó la expresión indigenismo cultural para designar obras no costumbristas ni de denuncia, sino recreaciones de mitos y leyendas que ponen especial énfasis en el tono poético con que están contadas".

8 "Con César Rodríguez Chicharro podemos decir que, mientras la novela indianista -como la llamó la puertorriqueña Concha Meléndez- es romántica y pinta los aspectos externos con una emoción exotista, la indigenista muestra al indio con sus cualidades y defectos. Mientras ésta alude airadamente a las miserables condiciones de vida del indígena, aquélla lo idealiza y lo describe estilizado y bello [...] La novela indianista [...] tuvo acogida como refuerzo del nacionalismo, intensificado a raíz de la Independencia e hizo una interpretación utópica de la vida americana pre-colombina".

9 A partir del trabajo María García Amilburu y Ramiro de Maeztu, se entenderá como la narración que 
Con frecuencia se han hablado del indigenismo literario sin ofrecer una definición, centrándose en una caracterización de las formas en que supuestamente se manifestó en la literatura desde finales del siglo XIX y durante las primeras décadas del siglo XX. En algunos casos se reconoce la existencia de un "indigenismo modernista", que por lo general se considera en forma desvalorativa, bien sea porque se identifica el modernismo con el Porfiriato y lo europeizante, o porque se valoran como más "evolucionados" otros movimientos literarios posteriores, y se considera al indigenismo modernista superficial, idealizante e incluso caricaturesco, sin ofrecer pruebas de lo que se afirma, sin atender la literalidad de las obras. En otras ocasiones, se niega la existencia de un indigenismo modernista y se señala que el indigenismo solo figuró en la literatura luego de que se abandonaron los modelos "afrancesados", es decir, cuando se abandonó el modernismo. Vamos a referirnos únicamente a algunos ejemplos de lo antes señalado, que constituye el eje de las generalizaciones más difundidas que rechazamos.

Rubén Barreiro Saguier apuntaba, en su trabajo titulado "Encuentro de culturas" (1972), una caracterización del indigenismo de las primeras décadas del siglo XX, que fue repetida, con algunas variantes, por numerosos estudiosos:

[...] pese a la ideología de reivindicación del indio, su lenguaje ha seguido siendo el del modernismo [...] Se emplearon palabras, se mechó la escritura con expresiones más o menos indígenas, pero el criterio de selección en gran medida continuaba orientado por el exotismo modernista. La simpatía por el indio no sobrepasó el cuadro de un interés superficial, desconocedor de los elementos constitutivos reales de su cultura (Barreiro, 1972, p. 29).

Por su parte, Ezequiel Maldonado, al estudiar la narrativa indigenista, que él considera tuvo su principal desarrollo en el medio rural, afirma que en ella se produce una "idealización del universo indígena frente al mundo hostil exterior” (1996, p. 43). Considera también que "En la década de los veintes se vislumbra en Latinoamérica el despertar de una conciencia artística" y al mismo tiempo que el "afrancesamiento de nuestras culturas cede [...] nuestra intelectualidad empieza a valorar su propia cultura y torna la mirada al indio" (Maldonado, 1996, pp. 44-45). Este autor considera también que: "el escritor mestizo percibirá al indio en un universo armónico, en cierta forma idealizado, donde los conflictos provienen del exterior, de la presencia del hombre blanco que depreda, viola, roba" (Maldonado, 1996, p. 47) y que la narrativa indigenista en México solo se desarrollaría hacia finales de la segunda década del siglo XX y estrechamente ligada a la llamada narrativa de la Revolución. En el enfoque de este investigador, como en el de otros estudiosos, se expresa tácitamente que la literatura anterior queda colocada en un lugar de inferioridad respecto a la narrativa que se desarrolló después, principalmente porque se le adjudica una falta de "autenticidad" y una visión superficial de la realidad indígena. Esta misma visión se puede observar también en algunos autores que reconocen la presencia del tema indígena y la problemática social indígena en obras literarias producidas desde finales del siglo XIX, es el caso de Susana Bautista Cruz:

[...] durante el siglo XIX, aun sin ser primordial, el indígena aparecería en cuentos, novelas y crónicas de la época, aunque enmarcado dentro de concepciones de influencia occidental que tendían a caracterizarlo de manera distorsionada y casi caricaturesca, en el marco de una supuesta inferioridad. Después de la Revolución mexicana, la narrativa indígena comenzó a recuperar la visibilidad social del indígena como tal (2009, p. 233).

enfatiza los aspectos descriptivos, derivada de la observación durante el trabajo de campo, sobre las costumbres de un pueblo, narración que involucra un informe contrastado con teorías científicas sobre determinados fenómenos culturales y sociales, con fines hermenéuticos e interpretativos. 
Este tipo de generalizaciones sobre las representaciones literarias del indígena, en el siglo XIX y principios del XX, figuran en diversos trabajos (Rodríguez, 1976, pp. 141-142; Bellido, 1996, p. 81; Bautista, 2009, p. 233; Alemany, 2013, p. 87) -obras que se limitan a resumir lo señalado sobre el tema por otros autores hace más de medio siglo (Meléndez, 1961) y en las que se tomaron en cuenta solo un conjunto de novelas, descuidando totalmente otros géneros-generalizaciones que han gozado de tan amplia difusión que toda obra que contraviene este esquematismo, pasa a ser considerada como caso de excepción, y no como un texto que hace visible la simplificación y el enfoque ideológico que modeliza las afirmaciones generalizadas y en las que en algunos casos se llega a oponer de manera antitética indigenismo y modernismo, o indigenismo y propuestas narrativas que integran una perspectiva cosmopolita, olvidando que el modernismo fue también una literatura de reivindicación de lo nacional, regional, y local, y adjudicándole a las políticas posrevolucionarias el abordaje "visible" del indígena.

Al margen de la importancia que le demos al rechazo de Alfonso Reyes a ser adscrito al modernismo, o a las distinciones tajantes entre el mundonovismo, que fue definido en su propio contexto como continuador del modernismo: "El Mundonovismo, viene a adaptar a nuestro espíritu y a nuestro medio las verdaderas conquistas realizadas por el movimiento anterior, el Modernismo" (Contreras, 1919, pp. 101-115) ${ }^{10}$ al que se le adscribió, aunque algunos investigadores identificarían totalmente modernismo y mundonovismo y otros señalarían, como Arturo Torres-Ríoseco: "Mundonovismo o Novomundismo es la tendencia temática de la poesía de la última fase del Modernismo" (González, 1972, p. 8); la estética modernista deja huellas discursivas en los enunciados del texto de Reyes, al mismo tiempo que se coloca al indio en lugar protagónico. Lo señalado es importante, porque si en muchas críticas e historias de la literatura se ha desvalorado el llamado "indigenismo modernista", al que se ha llegado a considerar como una modalidad del "exotismo" (Bermejo, 2002, p. 103)11, otro grupo de investigadores han identificado en ese movimiento el inicio del indigenismo contemporáneo en la literatura. Así por ejemplo, Trinidad Barrera observará, para el caso de Perú, aunque encontrando paralelos en México, algunas relaciones que entre los modernistas y el indigenismo peruano se produjeron:

Entre los poetas peruanos de principios del XX, modernistas aún [...] hay que citar a Abraham Valdelomar [...] En los últimos años de su vida propuso un sentido criollista o nacionalista a la literatura pero sin cortar los lazos totales con el modernismo. Fue fundador de la revista Colónida, en 1916 de la que salieron cuatro números, que está considerada como la iniciadora del indigenismo peruano reciente (Barrera, 2004, pp. 32-33).

Entre otros autores, Mercedes Serna señalará respecto a José Martí:

Las raíces del indigenismo militante de Martí pueden hallarse en [...] el escrito para "El Progreso", de Guatemala [...] fechado el 22 de abril de 1877, en el que arremete contra la conquista española [...] y en su "drama indio", escrito en Guatemala en 1877, Patria y libertad, Martí reivindica al indio frente al poder explotador de la Iglesia, el colonialista o el cacique [...] En La Edad de Oro, cuyo primer número salió en julio de 1889, su militancia indigenista se nos revela, igualmente, en los "Tres Héroes", en su oración sobre Bolívar, de 1893, en "Las ruinas indias", o en "El Padre Las Casas". [...] Martí busca la conjunción, de difícil consecución, entre indigenismo y universalismo [...] en su ensayo Nuestra América (Serna, 2011, pp. 209-210).

Marco Antonio Rodríguez Murillo señalará sobre el modernismo:

10 Obra publicada originalmente en 1917 en el Mercure de France, con el título de "Le mondonovisme".

11 "Para los modernistas, el indio representó una fuente de exotismo y un símbolo de universalidad que expresa las raíces auténticas de América”. 
fue también hacia el pasado de la misma Hispanoamérica, realizando una introspección (aunque todavía escueta) hacia las culturas indígenas, no sólo con el fin de que la identidad obtenida proviniera de las raíces más profundas, sino como manifestación en contra del orden colonial y neocolonial (Rodríguez, 2013, p. 85).

Rodríguez (1990) identifica en la obra de otro autor modernista la más clara expresión del indigenismo: "Habrá que esperar hasta que se produzcan la denuncia de la explotación del indígena -su más drástica instancia corresponde a Manuel González Prada-, y el planteamiento de la necesidad de su libración" (p. 41).

Aunque mucho se ha escrito y debatido en torno a las definiciones y las variadas modalidades desarrolladas sobre el tema del indígena en la literatura producida en Hispanoamérica, descalificando propuestas y autores a partir de una esgrimida falta de autenticidad al representar al indígena y su cultura, vamos a citar aquí las palabras de José Carlos Mariátegui, que Antonio Cornejo Polar, en uno de sus estudios sobre el tema, considera que señalan "el mejor rumbo" (Cornejo, 1997, p. 460) para comprender ese vasto movimiento:

[...] la mayor injusticia en que podría incurrir un crítico, sería cualquier apresurada condena de la literatura indigenista por su falta de autoctonismo integral o la presencia, más o menos acusada en sus obras, de elementos de artificio en la interpretación y en la expresión. La literatura indigenista no puede darnos una versión rigurosamente verista del indio. Tiene que idealizarlo y estilizarlo [...] Es todavía una literatura de mestizos. Por eso se llama indigenista y no indígena (Mariátegui, 1979, p. 306).

Esa diferencia entre literatura indigenista y literatura indígena es sumamente pertinente. Sobre las relaciones específicas entre el indigenismo y el modernismo en nuestro país, Martha Eliza López Pedraza y Juan Cristóbal Cruz Revueltas señalarán aspectos que otros investigadores también reconocen:

\footnotetext{
El modernismo mexicano es un movimiento que aporta importantes luces a la historia de la estética mexicana y a los modos de construcción de la imagen de "lo mexicano". De aquí la necesidad de revalorar este periodo a partir de algunas de sus figuras más prominentes. Ello permite constatar que el periodo revolucionario no representa necesariamente, [...] como se ha pretendido, una ruptura en la construcción de una narrativa y de una identidad nacional con respecto al periodo inmediato anterior. Temas como el indigenismo, el mestizaje y la idea misma de nación se construyen más acentuadamente desde las postrimerías del Porfiriato (López y Cruz, 2015, p. 163).
}

De estas palabras deriva también la importancia que adquiere el estudio de este relato de Alfonso Reyes.

\section{Conclusiones}

Nos hemos detenido en el tema del indigenismo porque el análisis del relato de Alfonso Reyes nos demuestra que esta obra debería integrarse al estudio del desarrollo de dicho tema en la literatura hispanoamericana y mexicana, no solo porque en él el tema del indio es el asunto principal, también por la forma en que se aborda en el texto.

El primer cuento de Vida y ficción de Alfonso Reyes, "Silueta del indio Jesús", previo a la escritura de otros relatos en los que lo europeo, la exploración en lo irracional, lo fantástico y otros puntos de relación con la estética modernista se hacen manifiestos, nos demuestra que en la primera década del siglo XX y antes de que el indigenismo se transformara en una política del estado posrevolucionario en México, el tema del indio no era tratado solo de la manera en que algunas generalizaciones han querido mostrar. 
Además, la presencia de la astuta estrategia narrativa utilizada por Reyes, que conmina al lector a evaluar a los dos personajes principales de su relato: protagonista y narrador, nos lleva a plantear una reflexión seria sobre la problemática que se presenta en el texto. De tal manera que el relato implica el propósito de hacer tomar una postura frente al tema del indio, sus acciones, sus valores, su cultura, la idealización y la desvaloración de que es objeto, las interrogantes que ofrece su proceder, en el contexto de una anécdota ocurrida en circunstancias "realistas" o verosímiles y contemporáneas a la escritura de su cuento, se aleja de todo enfoque moralizante y paternalista.

Lo señalado entra en contradicción con las caracterizaciones formuladas sobre la literatura de la época en México que han gozado de mayor difusión, y con el hecho de que el padre de Alfonso Reyes fuera un destacado militar del Porfiriato, que combatió contra Madero en la Revolución. Sin embargo, el afecto que Reyes manifestó hacia su padre no constituye argumento que nos faculte para identificar una identidad de posturas ideológicas entre uno y otro, mucho menos cuando tales posturas no han sido debidamente analizadas.

Los resultados de este breve estudio también parecerían entrar en contradicción con el posterior "rechazo" de Reyes a ser adscrito al modernismo, quien se mostraría más favorable a no ser "clasificado"; pero debemos tomar en cuenta que la adscripción o rechazo de un artista a un movimiento, no siempre es coherente con las características de sus obras, además, sabemos que en el caso de Reyes hubo tanto motivos personales (Pacheco, 1975, pp. 153-159) ${ }^{12}$, como algunas diferencias estéticas respecto a ciertas tendencias que se produjeron dentro del modernismo ${ }^{13}$, movimiento estético y literario que manifestó modalidades muy variadas en las distintas producciones, incluso de un mismo autor.

Consideramos que es necesario tomar en cuenta que en las diversas obras de un escritor -adscrito o excluido de determinado movimiento-, se producen puntos de contacto y de distancia respecto a los estilos históricos que le son contemporáneos; y que las clasificaciones suelen cumplir con un papel didáctico, más que descriptivo analítico, lo que hace que con frecuencia los análisis de las obras descubran aspectos que contradicen o matizan algunas afirmaciones generales. Por lo que deberíamos darle la misma importancia a las diferencias observadas en las similitudes que la importancia que suele dársele a la similitud en las diferencias cuando estudiamos elementos modernistas en la obra de un autor o cuando comparamos el tratamiento dado al tema indígena en la literatura mexicana en distintos periodos.

Debemos reconocer que el mundonovismo, al que se adscribió luego a Reyes, no fue contrario al modernismo, sino una vertiente del mismo, que puso el énfasis en lo que consideraba propio del "Nuevo Mundo" (Colombi, 2008, pp. 544-566 y Perea, 2010) y cuyo germen está dentro de tendencias que ya se producían en el movimiento modernista (Calderón, 2004, pp. 52-61), que no fue una propuesta meramente europeizante y que representaba de manera idealizada o caricaturesca al indio, los modernistas también se identificaron con lo autóctono y abordaron sus variados aspectos, aunque se suscitaron posturas diferenciadas, no solo respecto a la forma en que se caracterizaba lo nacional y se trataban sus diversas problemáticas, sino también frente a los problemas de los indígenas y su representación.

12 Sobre las relaciones de Alfonso Reyes con diversas tendencias estéticas (modernismo, vanguardia, negritud, barroco), se puede consultar Eugenio Florit (1957, pp. 1-51, separata) y Rogelio Arenas (2004, pp. 106-107, nota 16).

13 Su ensayo sobre Julio Ruelas lo hace visible, por ejemplo. 
Los elementos analizados en el texto resultan acordes a lo que el propio Reyes expresaría en 1922, al escribir, recordando las palabras de Antonio Mediz-Bolio a quien le dirigía una carta: "Se habla de la redención política del indio mucho más que [...] de su incorporación, explicada y aceptada, como elemento formativo de nuestra alma actual -con ser ello una tarea indispensable y previa a la política, como lo es la idea con respecto a la acción" (Reyes, 1989b, p. 422).

El estudio muestra la forma en que el indigenismo modernista que se manifiesta en "Silueta del indio Jesús" rompe con algunas generalizaciones formuladas sobre esta manifestación literaria, al mismo tiempo que revela las estrategias narrativas de un autor que confía en el sentido crítico de sus lectores para plantearles una necesaria reflexión sobre un problema social nacional que aún no ha sido resuelto, presentado en su relato desde un enfoque humanista y agudamente crítico, mediante la confrontación de dos perspectivas: el enfoque el narrador-personaje de la historia y el enfoque que deriva de las acciones y palabras del protagonista indígena del relato.

\section{Bibliografía}

Acevedo, R. L. (2002). El discurso de la ambigüedad: La narrativa modernista hispanoamericana. San Juan (Santo Domingo): Isla Negra Editores.

Aguirre, B. G. y Pozas, A. R. (1954). La política indigenista en México: Métodos y resultados. Ciudad de México: Instituto Nacional Indigenista.

Alemany Bay, C. (2013). La narrativa sobre el indígena en América Latina. Fases, entrecruzamientos, derivaciones. Acta Literaria, 47, 85-99.

Albizúrez, F. (1988). Poesía centroamericana posmodernista y de vanguardia. Guatemala: Editorial Universitaria.

Arenas, R. (2004). Alfonso Reyes íntimo: Oración del 9 de febrero. Materialidad verbal discursiva. Biografía y autobiografía. En P. P. Karic y F. Chávez Pérez (Eds.), Alfonso Reyes: perspectivas críticas, ensayos inéditos (pp. 97-120). Monterrey: Plaza y ValdésTecnológico de Monterrey.

Barrera, T. (2004). Perú, tradición y modernidad, vanguardia e indigenismo. América sin nombre, 5(6), 31-37.

Barreiro Saguier, R. (1965). El indigenismo en las novelas de la guerra del Chaco. TILAS, 7 , 727-734.

Barreiro Saguier, R. (1972). Encuentro de culturas. En C. Hernández Moreno (Ed.), América Latina en su literatura (pp. 21-40). México: UNESCO/Siglo XXI.

Bautista Cruz, S. (2009). De la literatura indigenista a la literatura indígena. En XVII Jornadas Lascasianas Internacionales. Contacto y operación a través de las fronteras (pp. $227-$ 241). México: UNAM.

Bellido Navarro, P. (1996). La visión indigenista en la novela de la revolución mexicana. En M. E. Barroso Villar (Coord.), Narrativa de la Revolución Mexicana: la revolución en las artes y en la prensa (pp. 81-91). Granada: Universidad de Granada.

Bermejo, M. C. (2002). El indigenismo. En Antología critica de escritores representativos de la Literatura Mexicana contemporánea (pp. 107-111). México: UNAM. 
Borges, J. L. y Reyes, A. (1998). La máquina de pensar y otros diálogos literarios. Ciudad de México: Secretaría de Educación Pública /Asociación Nacional del Libro / Cámara Nacional de la Industria Editorial Mexicana.

Brading, D. A. y Urquidi, M. L. (1989). Manuel Gamio y el indigenismo oficial en México. Revista Mexicana de Sociología, 51(2), 267-284.

Calderón de Puelles, M. (2004). Espacio modernista. Una mirada abarcadora. Revista de Literaturas Modernas, 34, 51-65.

Castañón, A. (2005). Trazos. Para una bibliografía comentada de Alfonso Reyes, con especial atención a su postergada antología mexicana: En busca del alma nacional. Revista de la Universidad de México, 15, 23-37.

Castañón, A. (2007). Alfonso Reyes, caballero de la voz errante. Monterrey: Universidad Autónoma de Nuevo León.

Colombi, B. (2008). Camino a la meca: escritores hispanoamericanos en Paris (1900-1920). En J. Myers (Coord.), Historia de los intelectuales en América Latina. Tomo I (pp. 544-566). Madrid: Katz.

Contreras, F. (1919). Mundonovismo. Varillita de virtud. Memoria Chilena (pp. 101-115). Santiago de Chile: Minerva.

Cornejo Polar, A. (1977). Para una interpretación de la novela indigenista. Casa de las Américas, 18(100), 40-48.

Cornejo Polar, A. (1978). El indigenismo y las literaturas heterogéneas: su doble estatuto social-cultural. Revista de Crítica Literaria Latinoamericana, 4(7-8), 7-21.

Cornejo Polar, A. (1979). La novela indigenista: un género contradictorio. Texto crítico, 5(14), 58-70.

Cornejo Polar, A. (1997). El indigenismo y las literaturas heterogéneas: su doble estatuto sociocultural. En S. Sosnowski (Coord.), Lectura crítica de la literatura americana (pp. 451- 466). Caracas: Ayacucho.

Curtius, E. R. (1976). Literatura Europea y Edad Media Latina. (Tomo I). México: Fondo de Cultura Económica.

Chang-Rodríguez, E. (2009). José Carlos Mariátegui y la polémica del indigenismo. América sin nombre, (13-14), 103-112.

Escajadillo, T. G. (1972). La narrativa indigenista: un planteamiento y ocho incisiones. Lima: Universidad Nacional Mayor de San Marcos.

Espejo, B. (2004). Alfonso Reyes y las maravillas de la prosa breve. En P. P. Karine y F. Chávez Pérez (Coords.), Alfonso Reyes: perspectivas críticas, “Ensayos inéditos” (pp. 231244). Barcelona: Plaza y Valdés.

Favre, H. (1998). El indigenismo. México: Fondo de Cultura Económica.

Florit, E. (1957). La obra poética. En A. Iduarte, E. Florit y O. Blondet (Coords.), Alfonso Reyes: vida y obra. Tomo II (pp. 1-51) New York: Hispanic Institute.

García Amilburu, M. y de Maeztu, R. (1999). La antropología contemporánea como una forma narrativa. Thémata: Concepciones y narrativas del yo, 22, 113-118. 
García, V. P. (1987). El Modernismo. La pasión por vivir el arte. Barcelona: Montesinos.

González, A. (1972). El novomundismo en la prosa de ficción de Altamirano. La Palabra y el Hombre, 4, 8-12.

Gullón, R. (1962). Indigenismo y modernismo. Revista de la Universidad de México, 3, 18-20.

Gullón, R. (1979). El modernismo visto por los modernistas, Madrid: Guadarrama.

Gullón, R. (1990). Direcciones del modernismo. Madrid: Alianza.

Gutiérrez Girardot, R. (1987). Modernismo. Supuestos históricos y Culturales. Bogotá: Universidad Externado de Colombia-Fondo de Cultura Económica (1 ed.).

Gutiérrez Girardot, R. (2004). Modernismo. Supuestos históricos y culturales. México: Fondo de Cultura Económica.

Jiménez, J. R. (1992). Antología crítica de la poesía modernista hispanoamericana. Madrid: Hiperión.

Jozef, B. (1991). Historia de la Literatura Hispanoamericana. Guadalajara: Universidad de Guadalajara.

Korsbaek, L. y Sámano Rentería, M. A. (2007). El indigenismo en México: antecedentes y actualidad. Ra Ximhai, 3(2), 195-224.

Leal, L. (1953). Teoría y práctica del cuento en Alfonso Reyes. Revista Iberoamericana, 31(59), 101-108.

León-Portilla, M. (1975). Trauma cultural, mestizaje e indigenismo en Mesoamérica. Cuadernos Americanos, 201(4), 113-133.

Litvak, L. (1990). España 1900: modernismo, anarquismo y fin de siglo. Barcelona: Anthropos.

López Pedraza, M. E. y Cruz Revueltas, J. C. (2015). Modernismo, pasado-presente. El México de Saturnino Herrán. Zintzun. Revista de Estudios Históricos, 61, 163-178.

Luna Sellés, C. (2002). La exploración de lo irracional en los escritores modernistas hispanoamericanos: literatura onírica y poetización de la realidad. Santiago de Compostela: Universidad de Santiago de Compostela.

Maestre, A. (2010). Hispanoamérica: Diccionario Alfonsino. Letras Libres, 100, 24-34.

Maldonado, E. (1996). El indigenismo literario. Temas y Variaciones de Literatura, 8,43-61.

Mamour Diop, P. (2007). Recorrido de la literatura indigenista del siglo xx en Latinoamérica: análisis de una muestra de novelas. Ogigia: Revista electrónica de estudios hispánicos, $1,31-40$.

Mariátegui, J. C. (1928). 7 ensayo de interpretación de la realidad peruana. Lima: Biblioteca Amauta.

Mariátegui, J. C. (1979). Siete ensayos de interpretación de la realidad peruana. México: Ediciones Era.

Martín, M. (1976). El cuento mexicano modernista: fundación epistemológica y anticipación narratológica de la vanguardia. En S. Poot Herrera y P. Brecia (Eds.), El cuento mexicano, Homenaje a Luis Leal (pp. 99-125). México: UNAM. 
Martínez, J. L. (1989). Introducción. En Alfonso Reyes, Ficciones. Obras completas. Tomo XXIII (pp. 7-20). México: Fondo de Cultura Económica.

Mejía Sánchez, E. (1970). Introducción. En Alfonso Reyes, Antología de Alfonso Reyes (pp. 3-46). México: Promexa.

Meléndez, C. (1939). La literatura indianista en el Perú de hoy. Primer Congreso Internacional de Catedráticos de Literatura Iberoamericana (pp. 99-109). México: Universidad Nacional Autónoma de México.

Meléndez, C. (1961). La novela indianista en Hispanoamérica (1832-1889). Río Piedras: Ediciones de la Universidad de Puerto Rico.

Meléndez, C. (1995). Ficciones de Alfonso Reyes. Alfonso Reyes. Antología y cartas de sus amigos. San Juan: Universidad de Puerto Rico.

Mijangos Díaz, E. y López Torres, A. (2011). El problema del indigenismo en el debate intelectual posrevolucionario. Signos Históricos, 13(25), 42-67.

Orizaga, D. (2012). Diario brasileño: Affonso Reis 1930-1936. En J. Sánchez, J. Pulido, R. Culebro (Coords.), Facciones. Ensayos sobre Alfonso Reyes (pp. 53-62). Xalapa: Universidad Veracruzana.

Oviedo, J. M. (2001). Historia de la Literatura Hispanoamericana. 3. Postmodernismo, vanguardia, regionalismo. (Tomo III). Madrid: Alianza.

Pacheco, J. E. (1975). Nota sobre una enemistad literaria: Reyes y López Velarde. Texto Crítico, I(2), 153-159.

Pacheco, J. E. (1976). La patria perdida: notas sobre Clavijero y la cultura nacional. En H. Aguilar Camín, J. J. Blanco, N. Girón, C. Monsiváis, J. E. Pacheco y S. Varese (Eds.), En torno a la cultura nacional (pp. 15-50). Ciudad de México: Secretaria de Educación Pública-Instituto Indigenista.

Portal, M. (1975). Narrativa indigenista mexicana de mediados de siglo. Cuadernos Hispanoamericanos, 298, 196-207.

Paz, O. (1950). El laberinto de la soledad. México: Cuadernos Americanos.

Peralta, V. (1995). Indigenismo, nacionalismo y modernidad en el Perú. En F. del Pino y C. Lázaro (Coords.), Visión de los otros y visión de sí mismos (pp. 272-292). Madrid: Arabí.

Perea San Martín, N. (2010). Modernismo y mundonovismo: apogeo, ocaso y vigencia actual. Biblioteca Virtual Miguel de Cervantes. Recuperado de http://letras-uruguay. espaciolatino.com

Perus, F. (1979). Literatura y sociedad en América Latina. México: Siglo XXI.

Rama, Á. (1976). José María Arguedas transculturador. En Señores e indios. Acerca de la cultura quechua (pp. 7-42). Buenos Aires: Arcas/Calicanto.

Rama, Ángel (1982). Transculturación narrativa en América Latina. Ciudad de México: Siglo XXI. Reyes, A. (1941). Pasado inmediato y otros ensayos. México: El Colegio de México. 
Reyes, A. (1953). Venganza literaria, en Árbol de pólvora, s.e., Publicada originalmente en México Moderno. Revista mensual de Letras y Arte, 5, 1920.

Reyes, A. (1955). Obras completas. (Tomo I). México: Fondo de Cultura Económica.

Reyes, A. (1956). Obras completas. (Tomo IV). México: Fondo de Cultura Económica.

Reyes, A. (1989a). Obras completas. (Tomo XXIII). México: Fondo de Cultura Económica.

Reyes, A. (1989b). Carta a Antonio Mediz-Bolio. En Obras completas. Tomo IV (pp. 421-424). México: Fondo de Cultura Económica.

Reyes, A. (1997). Pasado inmediato. En Obras completas. Tomo XII (pp. 172-278). México: Fondo de Cultura Económica.

Reyes, A. (2010). Prólogo. En Alfonso Reyes, Cuentos (pp. 7-20). México: Lumen.

Robb, J. W. (1989). Alfonso Reyes en busca de la unidad (constancia y evolución). Revista Iberoamericana, 55(148-149), 819-842.

Robb, J. W. (1991). Alfonso Reyes y el indio Jesús (una autobiografía poética). Revista Hispánica Moderna, 1(44), 138-143.

Rodríguez, L. (1990). El indigenismo como proyecto literario. Hispamérica, 19(55), 41-50.

Rodríguez Chicharro, C. (1976). Cuatro aspectos del modernismo. Texto Crítico, 2(4), 134-148.

Rodríguez Murillo, M. A. (2013). Modernismo y sociedad en la obra poética de Rubén Darío. Temas Antropológicos, Revista Científica de Investigaciones Regionales, 35(1), 81-107.

Rojas Garcidueñas, J. (1976). Indigenismo en el México de los siglos XVII a XIX. Revista de la Universidad de México, 30(7), 1-7.

Serna, M. (2011). Hispanismo, indigenismo y americanismo en la construcción de la unidad nacional y los discursos identitarios de Bolívar, Martí, Sarmiento y Rodó. Philologia Hispalensis, 25, 201-217.

Serrano Migallón, F. (2010). La pluma en la balanza. Lo jurídico en la obra de Alfonso Reyes. Lo jurídico en la obra literaria. Estudios Jurídicos, 70, 7-23.

Stavans, I. (1993). La pluma y la máscara. México: Fondo de Cultura Económica.

Schulman, I. (2002). El proyecto inconcluso. La vigencia del modernismo. México: Siglo XXI.

Todorov, T. (1987). La Conquista de América. El problema del otro. México: Siglo XXI Editores.

Todorov, T. (2004). Poética estructuralista. Madrid: Losada.

Toro, A. (1990). Semiótica y teatro latinoamericano. Buenos Aires: Galerna.

Torres, V.F. (2009). Del indianismo al indigenismo mexicano. Tema y variaciones de literatura, 32, 333-349.

Varas, P. (1996). Máscara vital y liberación estética en Delmira Agustini. En U. Cortazzo y A. Cáceres (Coords.), Delmira Agustini. Nuevas penetraciones críticas (pp. 132-157). Montevideo: Vintén. 
Villoro, Juan (1950). Los grandes momentos del indigenismo en México. México: El Colegio de México.

Warman, A. (1 de febrero de 1978). Indios y naciones del indigenismo. Nexos. Recuperado de https://www.nexos.com.mx/?p=3060

Yanuzzi Revetria, C. (2014). Traducir para crear: Alfonso Reyes en la literatura fantástica. En B. Greco y L. Pache Carballo (Eds.), Sobrenatural, fantástico y metarreal. La perspectiva de América Latina (pp. 205-216). México: Siglo XXI.

Zavaleta, C. E. y Jaime, S. Ch. (2003). El cuento en San Marcos siglo XX. Lima: Biblioteca Digital Andina. 
